DOI: https://doi.org/10.30749/2594-8261.v2n3p100-125

\title{
MEIO AMBIENTE E DANOS AMBIENTAIS ANÁLISE DOS MÉTODOS DE SOLUÇÃO DE CONFLITOS E TRIBUTAÇÃO
}

\section{ENVIRONMENT AND ENVIRONMENTAL DAMAGE ANALYSIS OF METHODS CONFLICT SOLUTION, AND TAXATION}

\author{
Guilherme Assis De Figueiredo* \\ Ailene De Oliveira Figueiredo*
}

\begin{abstract}
Resumo: O Direito Humano ao meio ambiente ecologicamente equilibrado, advém não somente da prevenção, mas também de sua reparação, neste contexto a possibilidade de utilização dos métodos consensuais de solução de conflitos nos processos judiciais ou administrativos que tenham por objeto o dano ambiental empresarial se revela de importante valia. O objetivo é demonstrar a possibilidade da utilização dos métodos consensuais de solução de conflitos, arbitragem, mediação e conciliação na esfera administrativa e judicial ambiental empresarial, apesar do meio ambiente ser considerado como direito indisponível. O método utilizado foi de pesquisa bibliográfica e documental, com fim metodológico descritivo, explicativo e propositivo. A importância da Tributação ambiental e a possibilidade de aplicação da Resolução 125 do CNJ e do novo CPC na esfera ambiental. Da Ordem de Dom João VI de 09/04/1809 de promessa de liberdade dos escravos e sugestão para proteção do meio ambiente. Conclusão pela possibilidade de utilização dos métodos consensuais de solução de conflitos nos processos judiciais e administrativos que tenham por objeto o dano ambiental.
\end{abstract}

Palavras-chave:Dano ambiental. Proteção ambiental. Métodos consensuais de solução de conflitos.

Abstract: The Human Right to the ecologically balanced environment, comes not only from prevention but also from its reparation, in this context the possibility of using the consensual methods of conflict resolution in judicial or administrative processes that have as their object the environmental damage of the company prove important value. The objective is to demonstrate the possibility of using consensual methods of conflict resolution, arbitration, mediation and conciliation in the administrative and judicial environmental business, despite the environment being considered as unavailable. The method used was bibliographic and documentary research, with a descriptive, explanatory and propositive methodological purpose.

\footnotetext{
* Mestrando em direito como aluno especial pela Universidade Federal de Mato Grosso do Sul- UFMS Especialista em Direito Civil e Processual Civil pela Universidade para o Desenvolvimento da Região do Pantanal- UNIDERP.

Atualmente é mestranda em Meio Ambiente e Desenvolvimento Regional e Sustentabilidade pela UNIDERP. Atua como defensora - Justiça Federal da $3^{\mathrm{a}}$ Região.
} 
The importance of environmental taxation and the possibility of applying CNJ Resolution 125 and the new CPC in the environmental sphere. From the Order of Dom João VI of 04/09/1809 of the promise of freedom of the slaves and suggestion for protection of the environment. Conclusion on the possibility of using consensual methods of conflict resolution in judicial and administrative proceedings that have as their object the environmental damage.

Keywords: Environmental damage. Environmental protection. Consensual methods of conflict resolution. 


\section{NOTAS INICIAIS}

A tributação ambiental é utilizada para fins de proteção ao meio ambiente não sendo a mesma de caráter punitivo, mas para fins de orientar e planejar a atividade empresarial, de forma a que através da prevenção o dano não ocorra ou mesmo se este vier a ocorrer a que haja medidas já previstas para a sua mitigação, pois bem, em ocorrendo o dano o mesmo deve ser objeto de reparação e indenização, e por ser um bem indisponível não cabe ao MP negociar ou acordar, no entanto surgem com a Resolução 125 do CNJ e o novo CPC a possibilidade de utilização dos métodos consensuais de solução de conflitos, poderiam os mesmos serem utilizados nos danos ambientais? Estes e outros questionamentos a respeito é que são objeto do presente artigo.

Com o advento da Resolução 125 do CNJ e do novo CPC/2015, os métodos consensuais de solução de conflitos passaram a ser colocados agora pelo Poder Judiciário, como mais uma das opções ao cidadão que busca a via judicial. Neste contexto estruturas novas são criadas, treinamento e capacitação são implementados para que tais métodos estejam à disposição da população como um sistema multiportas, visando por fim a redução da excessiva judicialização dos conflitos e a pacificação social.

Vários fatores levaram a implementação dos métodos consensuais de solução de conflito, entre eles a conhecida morosidade da justiça, os custos elevados, desgastes emocionais da disputa, pretensão de manutenção dos relacionamentos, recorribilidade excessiva, bem como a que no processo judicial não se visa a pacificação social.

A mediação, a conciliação e a arbitragem como métodos consensuais de solução de conflitos, aparecem neste contexto como parte das possibilidades de solução de tais problemas, visando sempre a pacificação social, através de composições obtidas pelas próprias partes na mediação, e/ou sugeridas na conciliação ou até mesmo decidida pelo arbitro, mas de qualquer forma acolhida pelas partes como a solução adequada ou possível do litígio.

No tocante ao meio ambiente e a tributação ambiental, verifica-se que por ser o meio ambiente um bem indisponível, qualquer lesão a este bem a princípio não 
poderia ser objeto de negociação por parte do Estado, o que impediria a utilização dos métodos consensuais de solução de conflitos, no entanto o princípio poluidorpagador a ser aplicado em casos de danos ambientais é permeado de várias relações entre poluidor e os atingidos diretamente pelo dano ambiental, tais como particulares, empresas, e o Estado, existindo ainda parte disponível em processos oriundos de danos ambientais que o próprio Estado através do Ministério Público poderia conciliar, visando o bem maior que é a recuperação dos danos ambientais, este é o desafio a ser enfrentado.

Com o advento da Resolução 125 do CNJ e do novo CPC/2015 a matéria atinente aos métodos consensuais de solução de conflitos, mediação, arbitragem e conciliação passam a ser utilizados de forma efetiva no Poder Judiciário, e ofertado por este, como novas possibilidades de soluções dos conflitos.

A estrutura necessária como instalações e capacitação de conciliadores e mediadores será criada pelo Poder Judiciário, sendo que ao distribuir a ação o Advogado já deverá informar se pretende a utilização dos métodos consensuais de solução de conflitos ou não, de qualquer forma a primeira audiência será de conciliação, quando mais uma vez as partes terão a possibilidade de optarem pela mediação, conciliação ou arbitragem.

$\mathrm{Na}$ Constituição do Império de 1824 a nossa primeira Constituição, as partes só seriam admitidas em juízo caso intentassem primeiramente a reconciliação (conciliação) em seu art.161 e 162, bem demonstrando que a busca da conciliação ou reconciliação é uma etapa lógica de qualquer conflito humano, sendo importante que a comunicação entre as partes envolvidas seja restabelecida, o que em vários casos resulta em solução do conflito.

A aplicação dos métodos consensuais de solução de conflitos aos danos ambientais à primeira vista éincompatível, com o conceito de indisponibilidade do meio ambiente, não sendo possível a aplicação de mediação, conciliação e arbitragem aos danos ambientais.

A problemática em suma é a possibilidade ou não da aplicação dos métodos consensuais de solução de conflitos, conciliação, mediação e arbitragem aos processos que versem por sobre danos ambientais e o conceito de indisponibilidade do meio ambiente. 
O método utilizado foi de pesquisa bibliográfica e documental, com fim metodológico descritivo, explicativo e propositivo.

\section{CONCEITO}

A mediação pode ser conceituada como método consensual de abordagem de conflitos, por um terceiro isento, sem poder decisório o qual facilitará a comunicação entre as partes auxiliando a estas no alcance da solução desejada a ser construída pelas mesmas. O art.1, parágrafo único da Lei 13.140/2015 define mediação como "É a atividade técnica exercida por terceiro imparcial sem poder decisório que, escolhido ou aceito pelas partes, as auxilia e estimula a identificar ou desenvolver soluções consensuais para a controvérsia". É interessante ressaltar que nos termos do art.515, §2 do CPC o consenso obtido na mediação incidental pode até mesmo versar sobre relação jurídica não deduzida nos autos (questões subjacentes ao conflito) e envolver sujeito estranho ao conflito, muito bem demonstrando a sua abrangência.

A conciliação é o método consensual de solução de conflitos efetivado pelo conciliador, em casos em que não exista vinculo anterior entre as partes e sem qualquer imposição ou constrangimento, visa a que as partes se conciliem, está estatuída no art.165, §2 do CPC e mesmo já sendo utilizada em juízo a mesma obterá força nova, pois haverá capacitação dos conciliadores para que os resultados sejam mais efetivos, não sendo mais o Juiz o conciliador.

A arbitragem é o método consensual de solução de conflitos pelo qual as partes por pacto privado delegam a um arbitro o poder de decidir a lide, devendo a mesma versar tão somente por sobre direitos disponíveis, pelos limites que forem estabelecidos de forma prévia pelas partes, sem intervenção do Poder Judiciário, a sua decisão é passível de execução judicial e da mesma não cabe recurso. É fundamentada pelos princípios da autonomia privada e da boa-fé objetiva, posto que as partes renunciam a jurisdição estatal em favor da jurisdição privada, se espera que a mesma cumpra o que for decidido sendo desnecessária a coerção estatal, por fim é bom que se diga que a arbitragem é voluntária no Brasil, posto que em outros países como os EUA há casos de arbitragem obrigatória como no Condado de 
Maricopa no Estado do Arizona em casos cujo valor da causa seja inferior a 50.000 dólares e no Estado da Pensilvânia nos mesmos termos e valores.

Leonardo de Faria Beraldo (BERALDO, 2014, p.44) leciona que o único entrave na possibilidade de se instituir a arbitragem de forma obrigatória no Brasil é o benefício da gratuidade da justiça, a qual inexiste na arbitragem, posto que o que foi garantido na CF/1988 em seu art.5, XXXV, foi o direito a tutela jurisdicional o que é da mesma forma garantida na arbitragem, nos seguintes termos:

[...]Encerramos com arrimo nas palavras de Pedro A. Batista Martins, que não vê óbice algum para eventual arbitragem compulsória no Brasil, pois, segundo ele o que a CF/88 quis garantir no art.5, XXXV, foi o direito à tutela jurisdicional. Ademais como todo os princípios constitucionais, bem como o dever de imparcialidade do arbitro, não haveria quaisquer inconstitucionalidades. Pedimos vênia para discordar de tal posicionamento, uma vez que o benefício da gratuidade da justiça não existe na arbitragem, e por se tratar de gastos mais elevados, pode ser que certas pessoas não tenham condições de arcar com os mesmos, inviabilizando-se, assim, a prestação efetiva e integral da tutela jurisdicional. Na nossa opinião, a princípio, o único entrave para a criação da arbitragem obrigatória no Brasil. (BERALDO, 2014, p.44).

Ressaltamos que é de grande importância o posicionamento do advogado perante o seu cliente, informando as vantagens da opção por qualquer uma das formas alternativas de solução do litígio, no entanto os atuais advogados na maioria das vezes durante a sua formação tiveram pouco ou nenhum contato com a matéria, sempre sendo formados na cultura demandista e não no manejo de mecanismos consensuais.

Os dois primeiros métodos consensuais de soluções de conflitos expostos, qual seja, mediação e conciliação são auto compositivos, já a arbitragem é heterocompositiva, posto que a decisão é delegada a um terceiro nomeado pelas partes, mas nem por isto deixa de ser um meio consensual de solução do litígio posto que as partes acordam por sobre quem será o arbitro e dependendo do conteúdo da demanda até mesmo se a lei nacional ou estrangeira será aplicável e outros ajustes feitos pelas partes, o que seria impossível em juízo.

Uma questão importante ainda aguarda uma resposta mais clara do Poder Judiciário, para que os métodos consensuais de solução de conflitos possam ser efetivamente um sucesso, qual seja, o questionamento a respeito da dupla cobrança 
de custas.

Senão vejamos, digamos que um cliente faça a opção por distribuir uma ação qualquer e não queira optar pelos métodos consensuais de solução de conflitos, deverá pagar as despesas processuais, depois, na primeira audiência que é de conciliação o cliente faz a opção pela a alternativa da mediação, neste caso deverá efetuar o pagamento de uma nova despesa do mediador ou mediadores e demais despesas inerentes ao conteúdo da demanda, posteriormente em havendo acordo e uma solução consensual na mediação o processo retornará ao Juiz para que o mesmo tão apenas homologue o acordo, não realizando qualquer outro ato, no entanto os valores da distribuição da ação não serão abatidos ou devolvidos ao cliente, resultando em cobrança de duas despesas.

Desta forma, vai ser difícil explicar ao cliente que o mesmo deverá pagar duas despesas, uma processual e a outra advinda da mediação (conciliação ou arbitragem), caso após a distribuição da ação faça opção por qualquer uma delas. 0 que era para ser barato ficou caro.

Ressaltando que as partes podem optar pelos métodos consensuais de solução de conflitos de forma extrajudicial, com o que pagariam tão somente um único valor, lembrando sempre que ainda falta a regulamentação à respeito na presente data.

\section{A EVOLUÇÃO HISTÓRICA NO BRASIL A RESOLUÇÃO 125 DO CNJ E O NOVO CPC}

Historicamente há notícias da utilização de soluções consensuais de conflitos em várias culturas (judaica, islâmica, hinduísta, budista, confucionista, indígena e cristã), existem citações bíblicas (Jó 33:23, Isaias 19:24, Hebreus 7:25), bem como na Grécia e China, nesta última há histórico de uso da conciliação à mais de 4.000 anos, existindo 10 milhões de conciliadores e tão somente 110 mil advogados no país (ideologia da pacificação social e harmonização), bem como demonstrando que a sua utilização é antiga e expressiva em determinados países.

No Brasil desde as Ordenações Filipinas de 1.603 e na Constituição do Império de 1824 (nossa primeira Constituição), em seu artigo 160, 161 e 162, 
constava a possibilidade de as partes nomearem árbitros, sendo que as sentenças seriam executadas sem possibilidade de recurso, muito parecido com as disposições sobre arbitragem atualmente.

Os art.161 e 162 da Constituição do Império de 1824 (BRASIL, 1824) determinavam que as partes não seriam admitidas em juízo sem que antes tivessem intentado a reconciliação, e efetivada a tentativa de solução amigável, demonstrando que a busca da conciliação ou reconciliação é uma etapa lógica de qualquer conflito, sendo importante que as partes restabeleçam a comunicação, para que a pacificação social ocorra, tanto o era em 1824 como o é em 2016, nada mais do que o desejado.

Art.160- Nas cíveis, e nas penaes civilmente intentadas, poderão as partes nomear juízes Arbitros. Suas sentenças serão executadas sem recurso, se assim convencionarem as mesmas Partes.

Art.161- Sem se fazer constar, que se tem intentado o meio da reconciliação, não se começará Processo algum.

Art.162-Para este fim haverá juízes de Paz, os quaes serão electivos pelo mesmo tempo, e maneira, por que se elegem os Vereadores das Camaras. Suas attribuições e Districytos serão regulados por lei. (BRASIL, Constituição1824.)

Mais recentemente em 1998 o Projeto de Lei 4.827-B/1998 da Deputada Zulaiê Cobra, institucionalizava e disciplinava de forma simples a mediação judicial ou extrajudicial como método de prevenção e solução consensual de conflitos, o qual poderia versar sobre a totalidade do conflito ou parte dele, em qualquer grau de jurisdição, sendo que o mesmo foi arquivado em 07/08/2006.

O CNJ - Conselho Nacional de Justiça no ano de 2010 editou a Resolução 125, tendo como objetivo organizar, uniformizar e aprimorar em âmbito nacional os métodos consensuais de solução de conflitos, evitando as disparidades de orientação e práticas, em especial as consensuais como a conciliação e a mediação, posto que são instrumentos de pacificação social e prevenção de litígios, visando por fim a redução da excessiva judicialização dos conflitos.

Visa a resolução 125 do Conselho Nacional de Justiça a criação dos núcleos permanentes de métodos consensuais de solução de conflitos, procurando a disseminação da cultura da pacificação social, buscando a cooperação das 
instituições públicas e privadas da área de ensino, OAB, Defensorias Públicas, Procuradorias, Ministério Público, empresas públicas e privadas, para que as mesmas programem práticas auto compositivas e as instituições de ensino criem disciplinas para a cultura da solução pacifica dos conflitos e também nas Escolas de Magistratura, no curso de iniciação funcional (juízes) e no curso de aperfeiçoamento.

Após a implementação haverá acompanhamento estatístico o qual servirá até mesmo para promoção ou remoção de magistrados, os mediadores deverão passar por cursos para obter certificado para atuação como mediadores, com regulamentação de código de ética.

Haverá gestão para inserção de práticas auto compositivas junto a empresas públicas, autarquias, agências reguladoras de serviços públicos em especial demandas que envolvam matérias já sedimentadas pela jurisprudência.

O CNJ através da Resolução 125 estabeleceu duas estruturas distintas para a aplicação da conciliação e mediação quer pré-processual, quer processual, sendo a primeira o Núcleo Permanente de Métodos Consensuais de Conflitos (núcleos), que terá como objetivo planejar e implantar essa política pública no respectivo tribunal e treinar e capacitar magistrados, servidores, conciliadores e mediadores.

A outra estrutura a ser implantada é a estrutura física dos Centros Judiciários de Soluções de Conflitos (centros), o qual será o local em que as sessões de mediação e conciliação pré-processual ou processual (caso o magistrado a encaminhe) serão realizadas.

O novo Código de Processo Civil foi sancionado em 17/03/2015 (projeto de Lei 8.046/2010), sendo que os institutos da conciliação e mediação foram inseridos nos arts. 3, §3, 148, II, 149, 165 a 175, 334, §4, estabelecendo os princípios informativos da conciliação e mediação (princípios da independência, da imparcialidade, da autonomia da vontade, da confidencialidade, da oralidade, da informalidade e da decisão informada) e a distinção entre ambas, sendo a mediação aplicável aos litígios em que já há ou se pretenda manter os vínculos entre as partes.Sendo que o mediador atua como um auxiliar as partes para que as mesmas cheguem per si a solução, sendo muito mais abrangente que a conciliação, posto que pode ser objeto de mediação questões que nem mesmo foram posta em juízo, 
já a conciliação é mais indicada para os casos em que não há vínculo anterior e nem se pretende a criação de vínculos futuros entre as partes, agindo o conciliador com sugestões de possibilidades de composição do litígio.

O trabalho de mediador e conciliador será objeto de registro de informações de performance, indicando o número de causas, o sucesso ou insucesso da atividade e divulgado o resultado do operador, dando mais transparência ao exercício da função e permitindo a população saber qual dos mediadores e conciliadores possui grau maior de sucesso.

É de ser ressaltar que a legislação nacional prevê a coexistência de "Câmaras privadas de mediação e conciliação", as quais em outros países como nos Estados Unidos da América estas empresas privadas se dedicam unicamente a desempenhar tais atividades, possuindo corpo técnico de conciliadores e mediadores profissionais, os quais possuem cursos e dominam as técnicas para a obtenção de êxito, sendo este mais um setor a que os empresários poderão se dedicar a explorar economicamente.

Humberto Theodoro Junior (JUNIOR, 2015, p.241,242) leciona que o novo CPC adota tendência de estruturar um modelo multiportas o qual acolhe a possibilidade jurisdicional e os meios alternativos para a solução do litígio, mesmo os não previstos em lei, que sejam a melhor solução para o caso, nos seguintes termos:

[...] Ao analisar o disposto no art.3 do novo CPC, percebe-se uma notória tendência de estruturar um modelo multiportas que adota a solução jurisdicional tradicional agregada à absorção dos meios alternativos (...). A mescla dessas técnicas de dimensionamento de litígios se faz momentaneamente necessária pela atávica característica do cidadão brasileiro de promover a delegação da resolução dos conflitos ao judiciário, fato facilmente demonstrável pela hiperjudicialização de conflitos, mesmo daqueles que ordinariamente em outros sistemas são resolvidos pela ingerência das próprias partes mediante autocomposição. Isso induzirá uma necessária mudança do comportamento não cooperativo e agressivo das partes, desde o início, sob a égide do CPC/2015, em face da possibilidade inaugural de realização de audiência de conciliação ou mediação do art.334. (JUNIOR, 2015, p.241,242). 
É bom que se diga que o art.175 do CPC adota uma postura aberta do sistema multiportas, acolhendo outras formas de mediação e conciliação extrajudiciais ou realizadas por profissional independente, a serem regulamentadas em lei específica, como possíveis de uso pelas partes.

O sistema multiportas é a possibilidade das partes em um litígio serem apresentadas as várias possibilidades de composição do conflito e de livre e espontânea vontade optarem por uma delas, quando serão avaliados os elementos de interesse das partes, tais como a celeridade, custos financeiros, desgastes emocionais da disputa, manutenção dos relacionamentos, recorribilidade excessiva e outros fatores que podem fazer que a opção seja outra a escolhida que não o processo judicial, perseguindo a pacificação dos conflitos.

Neste sentido leciona Cássio Scarpinella Bueno (BUENO, 2015, p.155)

[...] O art.175 ressalva a possibilidade de serem empregados outros meios extrajudiciais para a solução de conflitos. É o que os especialistas da matéria chamam de sistema multiportas, no sentido de deverem coexistir variadas soluções para viabilizar, além da conciliação, da mediação e da arbitragem, referidas pelo novo CPC desde os $\S \S 2,3$, de seu art.3, a solução extrajudicial mais adequada possível de acordo com as peculiaridades de cada caso concreto. (BUENO, 2015, p.155).

O nosso Poder Judiciário está pronto a solucionar conflitos de direito, mas não conflitos de interesses das partes, resultando sempre ao final em um vencedor $\mathrm{e}$ um perdedor, o famoso resultado "soma zero" nos quais o ganho de um significa sempre a derrota do outro e não a possibilidade do "soma não zero", no qual os participantes têm interesses comuns e opostos e a cooperação possibilita ganhos mútuos o que nos remete a Teoria dos Jogos no qual John Forbes Nash Jr., visualizou que seria possível pelo princípio do equilíbrio e através da cooperação obter resultados em que ambas as partes se sintam satisfeitas e mesmo em posterior análise das opções feitas não sintam remorso ou vontade de alterar o que foi obtido. 


\section{DA INDISPONIBILIDADE DO MEIO AMBIENTE}

O mestre José Rubens Maroto Leite leciona que "Como bem pertencente a toda a coletividade indistintamente, o meio ambiente é indisponível" (LEITE, 2015, p.42), desta forma à princípio verificamos que os métodos consensuais de solução de conflitos não poderiam ser aplicados nos processos que tenham por objeto o dano ambiental.

O art.3 da Lei de mediações (BRASIL, Lei 13.140 de 26 de Junho de 2015), determina que a mediação possui abrangência por sobre direitos disponíveis e os indisponíveis este último desde que admita transação, bem como pode versar sobre o todo ou parte do conflito e por fim em caso de direitos indisponíveis mas transigíveis será exigida a oitiva do MP, nos seguintes termos:

[...]Art.3- Pode ser objeto de mediação o conflito que verse sobre direitos disponíveis ou sobre direitos indisponíveis que admitam transação.

§1-A mediação pode versar sobre todo o conflito ou parte dele. §2-O consenso das partes envolvendo direitos indisponíveis, mas transigíveis, deve ser homologado em juízo, exigida a oitiva do Ministério Público. (BRASIL, Lei 13.140 de 26 de junho de 2015).

A conciliação está contemplada nas leis dos Juizados Especiais Cíveis e Criminais (Lei 9.099/95, arts. 21 a 26), tanto estaduais como federais (Lei 10.259/2001, art.10, parágrafo único), bem como no art.334 do CPC/2015 e da mesma forma que a mediação à princípio seria incompatível como conceito de indisponibilidade do meio ambiente.

Por fim temos a arbitragem que está normatizada na Lei 13.129/15 em seu art.1, §1, o qual somente permite a administração pública utilizar-se da arbitragem para dirimir conflitos relativos a direitos patrimoniais disponíveis, o que não seria o caso à princípio do meio ambiente.

Desta forma, inicialmente parece ser forçoso reconhecer que por ser um bem indisponível o Estado não poderia utilizar da conciliação, mediação ou 
arbitragem para os conflitos que envolvem o meio ambiente, estando impedido de assim proceder.

\section{DA TRIBUTAÇÃO AMBIENTAL E DA "ORDEM" DE 09/04/1809 EFETIVADA POR DOM JOÃO VI, DE PROMESSA DE LIBERDADE DOS ESCRAVOS, E A SUA APLICAÇÃO A NOSSA ATUAL REALIDADE AMBIENTAL COMO SINGELA PROPOSTA DE PROTEÇÃO DO MEIO AMBIENTE}

A fim de que possamos entender como a defesa do meio ambiente pode ser efetivada pela tributação ambiental, bem perceber como a relação tributaria e os processos que versam por sobre danos ambientais, quer cíveis quer penais se correlacionam, desembocando na possibilidade ou não da aplicação dos métodos consensuais de solução de conflitos, importante é a sua conceituação.

A tributação ambiental se utiliza de instrumentos econômicos para fins de proteção ao meio ambiente, visando a sua proteção, em nossa sociedade de risco global, a tributação ambiental têm basicamente um caráter incentivador e ordenatório, para fins de internalizar os custos ambientais da empresas, os quais serão repassados aos consumidores que também usufruem e portanto devem pagar pelo dano ao meio ambiente, para fins de que no futuro haja a diminuição dos impactos ou até mesmo a substituição das atividades empresariais que degradem o meio ambiente, protegendo a mesma para as futuras gerações, neste sentido quando o tributo ambiental vai além de arrecadar valores e passa a produzir efeitos de proteção ambiental possui caráter extrafiscal, com incentivos e benefícios fiscais.

Antes que se dentre nos conceitos de direito tributário e ambiental e seus princípios é necessário expor que o presente artigo deixará de expor por sobre todos os demais princípios e fundamentos de direito tributário e ambiental aqui não tratados, tais como o princípio da cooperação, da vedação do retrocesso e outros, pois os mesmos não guardam correlação com a matéria e não serão objeto do presente artigo.

José Rubens Morato Leite (LEITE, 2015, p. 216-217) leciona que a tributação ambiental é a utilização de instrumentos econômicos como proteção ao meio ambiente, sendo certo que a tributação ambiental não se trata de tributação punitiva, mas sim visa orientar o contribuinte a planejar o seu negócio com respeito a 
proteção ao meio ambiente e ao mais importante princípio ambiental que é a prevenção, para que o dano não ocorra, pois uma vez efetivado na maioria das vezes o mesmo é quase que irreparável,

[...] Em um primeiro momento, a tributação era visualizada somente como um instrumento para prover o erário público dos recursos necessários aos gastos indispensáveis, tendo cunho apenas fiscal. Ocorre que tanto a conjuntura quanto a estrutura econômica passam a cobrar medidas corretivas por parte do Estado, a fim de que ele seja não só um instrumento para obtenção de receita para a respectiva despesa pública, mas também um agente que provoque modificações deliberadas nas estruturas sociais.

$[\ldots]$

Portanto a tributação ambiental não se trata de uma tributação punitiva, na medida em que se busca orientar o contribuinte a planejar seu negócio licito de acordo com uma finalidade pretendida pelo constituinte, no caso a proteção do meio ambiente.(LEITE, 2015, p. 216-217).

Celso Antônio Pacheco Ferreira Fiorillo (FIORILLO, 2005, p.36,37) ao analisar as origens do atual direito ambiental tributário, demonstra que a Constituição Federal de 1988, em seus princípios fundamentais, guiam o sistema constitucional tributário brasileiro, sendo que a relação fisco-contribuinte têm por escopo o proveito do cidadão, cabendo ao Estado cumprir a sua função social, dentro de limites ao poder ativo de tributar, nos seguintes termos:

[...]Trouxe, ainda a nova Carta, entre seus princípios fundamentais e como fundamento do Estado Democrático de Direito brasileiro (art.1), a soberania, a cidadania, a dignidade da pessoa humana, os valores sociais do trabalho e da livre iniciativa e o pluralismo político.

Esses quatro primeiros artigos destacados por si só demonstram os contornos do Estado Democrático de Direito brasileiro a partir de 1988. Dessa forma, faz-se imperioso, curial, que qualquer análise sobre qualquer tema do direito positivo que se queira realizar após 1988, passe pela trilha iluminada pelos princípios fundamentais amparados e consagrados nestes quatro primeiros artigos da constituição em vigor.

[...] Com efeito, verificamos que a partir da promulgação da Carta de 1988 não se pode de forma alguma analisar a relação fiscocontribuinte ignorando que o valor maior da dignidade da pessoa humana foi alçado a fundamento da República Federativa do Brasil, assumindo nítida feição no sentido de situar a arrecadação de quantia em dinheiro advinda da atividade tributária como um todo, em proveito da pessoa humana, a fim de que o Estado possa cumprir 
com sua função social, assegurada pelo art.6 do Texto Maior, o chamado Piso Vital Mínimo....] (FIORILLO, 2005, p.36,37).

Após as definições acima a respeito do conceito de direito tributário ambiental, necessário se faz a conceituação do que seria meio ambiente, como uma interação entre homem e a natureza, a qual deve ser harmônica e sustentável para que a vida seja possível e com qualidade tanto da atual como de futuras gerações, efetivando a proteção de todas as formas de vida e suas interações. O conceito legal de direito tributário ambiental consta da Lei 6.938/81 em seu art.3, (BRASIL, 1981) a seguir exposto.

[...] Art.3- Para os fins previstos nesta Lei, entende-se por: I-Meio ambiente, o conjunto de condições, leis, influências e interações de ordem física, química e biológica, que permite, abriga e rege a vida em todas as suas formas; (BRASIL, 1981).

José Rubens Morato Leite, (LEITE, 2015, p.41) define meio ambiente, apud Virgílio Silva (SILVA, 2009), como "meio ambiente pode ser definido como o conjunto interativo de elementos naturais, artificiais, culturais e do trabalho, que propicia o sadio e o equilibrado desenvolvimento de todas as formas de vida", incluindo ao conceito os elementos culturais e do trabalho, que resultam na possibilidade de desenvolvimento de forma equilibrada da vida existente em nosso planeta.

Princípios importantes do direito ambiental são a preservação e precaução, tais princípios determinam que em caso de dúvida cientifica a respeito de qualquer produto ou processo se poluidor ou não, a dúvida trabalhará em benefício do meio ambiente princípio da precaução.

Já o princípio da prevenção assegura a eliminação dos perigos e riscos já conhecidos cientificamente o que gera obrigações de fazer ou não fazer, tendo como exemplos da operacionalização do princípio temos o estudo prévio de impacto ambiental e o licenciamento ambiental, posto que é muito difícil, custoso e as vezes impossível se restabelecer ao status quo ante a natureza destruída ou poluída em qualquer grau, merecendo portanto especial importância os referidos princípios. 
Conceituando o princípio da prevenção leciona Sarlete Fensterseifer (SARLET;FENSTERSEIFER, [20--?], p.160 apud ANTUNES, 2008):

[...]Conforme a lição de Paulo de Bessa Antunes, "o princípio da prevenção aplica-se a impactos já conhecidos e dos quais se possa com segurança estabelecer um conjunto de nexos de causalidade que seja suficiente para a identificação dos impactos futuros mais prováveis". A irreversibilidade de certos danos ambientais, como por exemplo a extinção de espécies da fauna e flora, reforça a relevância de se adotarem medidas preventivas, impedindo e proibindo a adoção de certas práticas antiecológicas. (SARLET; FENSTERSEIFER, [20--?], p.160 apud ANTUNES, 2008).

O princípio mais importante do direito ambiental é o princípio da prevenção que seria a utilização de todos os meios a disposição do Estado tais como o estudo prévio de impacto ambiental e o licenciamento ambiental e a fiscalização para fins de se evitar danos ao meio ambiente, neste sentido até mesmo a tributação ambiental é essencial para dissuadir qualquer pretensão de poluição e destruição do meio ambiente, preservando o bem maior para gerações futuras. Neste sentido leciona Sarlete Fensterseifer (SARLET;FENSTERSEIFER, [20--?], p.164apud ANTUNES, 2008).

[...] O princípio da precaução, como uma espécie de princípio da prevenção qualificado ou mais desenvolvido, abre caminho para uma nova racionalidade jurídica, mais abrangente e complexa, vinculando a ação humana presente a resultados futuros. Isso faz com que o princípio da precaução seja um dos pilares mais importantes da tutela jurídica do ambiente, e, consequentemente, seja reconhecido como um dos princípios gerais do Direito Ambiental moderno. O seu conteúdo normativo estabelece em linhas gerais, que diante da dúvida e da incerteza cientifica a respeito da segurança e das consequências do uso de determinadas substâncias ou tecnologias, o operador do sistema jurídico deve ter como fio condutor uma conduta precavida. (SARLET; FENSTERSEIFER, [20--?], p. 164 apud ANTUNES, 2008).

No entanto os danos ambientais ocorrem, tais fatos resultam por falhas humanas ou de equipamentos e máquinas, falhas cumuladas ou não, ou por simples desrespeito à lei e ganância, bem como várias outras razões.

Um dos princípios da tributação ambiental é o princípio pagador-poluidor, o qual ao contrário do que se lê não autoriza o empresário a poluir desde que pague 
por isso, muito pelo contrário o princípio pagador-poluidor visa prevenir a que o meio ambiente venha a sofrer qualquer dano, cobrando medidas várias que diminuam a possibilidade de dano, determinando ainda que tais custos sejam internalizados pelas empresas as quais repassarão aos consumidores tais custos nos preços de seus produtos, devendo estes também suportar os custos como consumidores das despesas inerentes a prevenção de danos ambientais. Um destes exemplos é o catalisador nos veículos automotores e que visa a diminuição das emissões de gases tóxicos e poluentes na atmosfera, sendo certo que o seu custo tanto de pesquisa como de produção foi efetivamente repassado aos consumidores, os quais são corresponsáveis com o princípio poluidor-pagador ao consumir um bem potencialmente danoso ao meio ambiente. O conceito de princípio poluidor-pagador é muito bem exposto por José Rubens Maroto Leite, (LEITE, 2015, p. 102-103) nos seguintes termos:

[...] O princípio poluidor-pagador (PPP) impõe a internalização pelo próprio poluidor, dos custos necessários à diminuição, à eliminação ou a neutralização do dano realizado no processo ou na execução da atividade.

[...] Podemos, então, considerar o princípio do poluidor-pagador através da ótica do poluidor primeiro pagador, importando em considerar que o poluidor, é antes de poluir, pagador. Pagador dos custos relativos às medidas preventivas e precaucionais, destinadas a evitar a produção do resultado proibido ou não pretendido, ou seja, é primeiro pagador, porque paga, não porque polui, mas paga justamente para que não polua. Assim, por exemplo, é a partir desse princípio que o poluidor deve investir em filtros em suas fábricas, evitando a emissão de poluição, bem como tratar os efluentes e se responsabilizar pelos resíduos gerados em decorrência dos seus processos produtivos. (LEITE, 2015, p. 102-103).

Os artigos muitas vezes podem ser efetivados com alguma perspectiva propositiva, esta é a intenção abaixo apresentada de forma muito restrita e limitada, como singela contribuição a discussão do tema.

Pois bem, se temos a defesa do meio ambiente muito bem definida em nossa Constituição Federal e demais legislação correlata porque a mesma não se efetiva, o que falta e o que pode ser feito para que tal defesa seja realizada? A resposta é simples "me dê uma razão". 
Dom João VI expediu a "Ordem de 09/04/1809 que prometia a liberdade aos escravos que denunciassem contrabandistas de madeira pau-brasil e tapinhoã"(TEIXEIRA, 2012, p.72). Imagino a correria o desespero dos escravos de localizar e denunciar um contrabandista, para obter a sua liberdade, esta era a sua razão, Dom João VI deu uma razão aos escravos para que a sua Ordem fosse efetivamente cumprida.

Qual é a razão dada ao povo brasileiro, ao cidadão mediano de denunciar danos ambientais? Teria ele a coragem de procurar o Ministério Público e denunciar, saberia de tal possibilidade? A consciência de que o meio ambiente deve ser defendido e preservado já existe incutida na população, mas faltam ainda mecanismos adequados para serem colocados a disposição do cidadão de forma simples e efetiva que permita ao mesmo denunciar e ver a máquina estatal efetivamente funcionar em defesa do meio ambiente, até mesmo de modo anônimo, se assim desejar.

Basta entrar em qualquer loja do comércio popular ou de um shopping Center e de imediato se verifica a existência de "um exemplar do CDC" à disposição do consumidor. Desta forma a defesa do consumidor se faz respeitar como um alerta ao próprio lojista que deve cumprir com as suas obrigações legais ou aquele conteúdo do CDC pode eventualmente ser utilizado contra o mesmo.

Medidas simples e efetivas podem ser realizadas à custo quase zero, porque não se exigir que placas sejam afixadas nas entradas das empresas com um "disque poluição", porque não se exigir que antes da implantação de empresas potencialmente poluidoras que as mesmas sejam obrigadas a fazer campanha publicitária na comunidade onde se localizam, sobre a possibilidade de se denunciar eventual poluição ou eminente perigo? Tais medidas dependem de legislação a ser criada, mas podem ser em curto espaço de tempo uma solução efetiva a que deixemos de se sermos escravos da ganância dos poluidores e passemos a liberdade da proteção do meio ambiente através da implantação de um "disque poluição", quando o cidadão poderá até mesmo anonimamente denunciar sem correr riscos de perder emprego ou ser vítima retaliação de vizinhos e empresários.

É de se pensar se nenhum dos funcionários da Samarco de Mariana/MG ao menos não desconfiava ou até mesmo tinha quase certeza, do que poderia ocorrer e 
deixou de denunciar por medo de perder o emprego ou de retaliação da empresa, se existisse um "disque poluição" com possibilidade de denúncias de forma anônima, a realidade poderia ser diferente? Fica a restrita e limitada sugestão a que se possa debater sobre o tema.

\section{DAS POSSIBILIDADES DE UTILIZAÇÃO DOS MÉTODOS CONSENSUAIS DE SOLUÇÃO DE CONFLITOS NOS PROCESSOS QUE TENHAM POR OBJETO O DANO AMBIENTAL}

De início parece haver uma total incompatibilidade entre a indisponibilidade do meio ambiente, posto que bem da coletividade e a possibilidade de utilização dos métodos consensuais de solução de conflitos, tais como a conciliação, mediação e arbitragem para os processos que tenham por objeto o dano ambiental, no entanto vários doutrinadores e até mesmo a realidade processual já demonstram uma mudança fática nas ações que envolvem o dano ambiental.

Edis Milaré (MILARÉ, 2015, p.1547) reconhece a possibilidade da utilização da conciliação nos casos de danos de menor poder ofensivo enquadrados na Lei 9.615/1998, que permite a aplicação da lei 9.099/1995, firmando compromisso com a justiça da conciliação, nos seguintes termos:

[...]Embora os crimes contra o meio ambiente se apresentem, a princípio, como atentados de graves consequências para o equilíbrio ecológico, não raras vezes despontam condutas tidas como de menor poder ofensivo, que clamam por soluções mais rápidas e simples, próprias da chamada justiça consensual.

É o que se vê na Lei 9.615/1998.

Como que para justificar a prodigalidade com que erigiu à condição de crimes figuras que melhor se acomodariam num quadro de contravenções ou de ilícitos administrativos, determinou essa Lei a aplicação de dispositivos da Lei 9.099/1995, aos referidos crimes, firmando assim, claro e decidido compromisso com a justiça da conciliação.(MILARÉ, 2015, p.1547).

Luis Fernando Guerrero (GUERRERO, 2015, p.54) em recente livro da Coleção Atlas de Processo Civil, com a coordenação do professor Carlos Alberto Carmona, possui uma visão diferenciada e inédita quanto a possibilidade de utilização dos métodos de solução de conflitos em danos ambientais, mesmo estes sendo indisponíveis, Luis Guerrero acredita que os caminhos que levam a 
concretização da transação entre o MP e o réu são muito maiores e extensos que se imagina, desta forma aplicável o é a utilização dos métodos consensuais de solução de conflitos de forma antecedente a obtenção da transação, seriam estas aplicadas previamente, "o art.840 do Código Civil, por sua vez, nada diz sobre as formas de obtenção da transação ou de que modo se chega a ela. Essa é a função dos métodos de solução de controvérsias, especialmente os métodos ditos consensuais", portanto não há vedação legal a sua utilização, devendo à bem da verdade tais parâmetros se ajustarem as alterações processuais havidas.

A terceira opinião favorável a aplicação dos métodos consensuais de solução de conflitos, voltados, no entanto para a arbitragem é de Leonardo de Faria Beraldo (BERALDO, 2014, p.89), que reconhece a possibilidade de aplicação da arbitragem em danos ambientais entre o particular atingido pelo acidente ambiental e o causador do dano, é o caso do pescador do dano da pousada, do restaurante no caso de um derramamento de óleo em uma cidade praiana, neste caso o dano ao particular pode sim ser objeto de arbitragem e dos demais métodos consensuais de solução de conflitos, nos seguintes termos:

[...] O particular que tenha sido direta ou indiretamente atingido pelo acidente ambiental também pode querer resolver a sua lide, com o causador do dano, por arbitragem. Pense-se, por exemplo, num derramamento de petróleo numa cidade praiana do nordeste brasileiro. Quantas pessoas dependem da pesca e do turismo para sobreviver?Não seria possível dirimir os danos causados a essas pessoas em processo arbitral, sem a presença do Ministério Público? A nosso ver, claro que sim. Vejam que o dano ao meio ambiente é uma coisa; já o dano causado ao particular (v.g., o pescador, ou o dono do restaurante ou da pousada da região) é outra totalmente diferente. (BERALDO, 2014, p. 89).

A quarta opinião favorável a aplicação dos métodos consensuais de solução de conflitos, vem de Tereza Pantoja (PANTOJA, 2007, p.92) ao analisar as possibilidades de utilização da arbitragem em direito ambiental afirma que o objetivo é a celeridade e a eficiência na solução dos litígios existentes, fazendoreferência expressa a possibilidade de utilização em cálculos de rateio atinente a solidariedade imposta aos agentes causadores do dano e outras possibilidades, nos seguintes termos: 
[...] Quaisquer outras disputas surgidas no seio de várias relações jurídicas abrangidas pelo que se convencionou denominar de direito ambiental podem ser solucionadas mediante arbitragem; são as relativas a valores patrimoniais ou estimativas de valores, são as questões atinentes ao rateio da solidariedade imposta aos agentes causadores do dano ambiental; são as questões referentes à mensuração pecuniária da periclitação da vida ou da saúde; são as situações verificadas tanto na composição do dano, como na estimativa dos mecanismos para a prevenção do mesmo, tanto mais eficiente será o desempenho dos agentes da política ambiental quanto mais especializada e celeremente se solucionarem os conflitos ai surgidos. (PANTOJA, 2007, p.92).

A quinta posição à favor da utilização dos métodos consensuais de solução de conflito em matéria ambiental é dada por Juliana Bonacorsi de Palma, (PALMA, 2015, p.271) que reconhece no TAC termo de ajustamento de conduta uma das possibilidades de sua efetivação, nos termos da Lei 7.347/1985 em seu art.5, §6 , até mesmo em matéria ambiental, nos seguintes termos:

[...] A questão se que se coloca na relação entre a consensualidade e legalidade concerne à possibilidade de a Administração Pública celebrar acordos administrativos sem previsão legal expressa. Ao contrário dos modelos analisados de Direito Comparado de atuação consensual, inexiste na lei federal de processo administrativo permissivo genérico para que a Administração Pública adote instrumentos consensuais. A figura que mais se aproxima de um permissivo genérico corresponde, porém, ao termo de ajustamento de conduta/TAC previsto na lei da ação civil pública (Lei 7.347/1985). A lei da ação civil pública rege as ações de responsabilidade por danos causados ao meio ambiente; ao consumidor; aos bens e direitos de valor artístico, estético, histórico, turístico e paisagístico; à ordem econômica e a economia popular; à ordem urbanística; e a qualquer outro interesse difuso ou coletivo (art.1). Dentre os legitimados para propor a ação civil pública estão a União, os Estados, o Distrito Federal e os Municípios, assim como os entes da Administração indireta - autarquias, fundações e empresas estatais(art.5) de forma que a Administração Pública direta e indireta está autorizada a celebrar TAC, nos termos do art.5, §6, desde que sua atuação guarde pertinência temática com o rol de objetos tutelados, os órgãos públicos legitimados poderão tomar dos interessados compromisso de ajustamento de conduta às exigências legais, mediante cominações, que terá eficácia de título executivo extrajudicial. (PALMA, 2015, p. 271). 
No Estado de São Paulo através do Decreto 52.201/2007, art.2 (SÃO PAULO, 2007) foi concedido um permissivo genérico para que toda a Administração Pública possa celebrar TAC, ressalvada as universidades estaduais, sendo esta uma ampla autorização legislativa a administração direta e indireta, podendo ser celebrada por Secretarias de Estado, autarquias, fundações e empresas estatais, para terminações consensuais dos processos administrativos de qualquer natureza, nos seguintes termos:

Art.2-Os termos de que trata 0 artigo anterior poderão ser celebrados:

I- Pelas Secretarias de Estado;

II- Pelas autarquias inclusive de regime especial, exceto as universidades públicas estaduais;

III- pelas empresas públicas e sociedades de economia mista, sob o controle do Estado, pela sua Administração centralizada ou descentralizada;

IV- Pelas fundações instituídas ou mantidas pelo Estado. (SÃO PAULO, 2007).

Após a exposição de vários doutrinadores que admitem a possibilidade de aplicação dos métodos consensuais de solução de conflito, cada qual com a sua percepção do momento e forma adequada, necessário se faz verificar qual é a realidade prática atualmente existente em nossos processos, para tanto a Comarca de Corumbá na região do Pantanal é uma das que registra grande volume de danos ambientais e portanto, serve de mero indicativo de parte da realidade processual em nosso Estado.

Verificado por simples levantamento processual via site do TJ/MS (www.tjms.jus.br), em Ação Civil Pública, o Ministério Público têm efetivamente realizado conciliação em audiência, normalmente em fase de execução, como se verifica nos autos da Comarca de Corumbá, Vara de Fazenda Pública e de Registros Públicos, 0800.4977.80.2014.8.12.0008 0802464.42.2014.8.12.0008(p.129), $\quad$ 0005829.50. 2008.8.12.0008 $\quad$ (p.700), 0802465.27.2014.8.12.0008 (p.179), acessado em 10/04/2016.

Bem demonstrando que o MP está comprometido com a proteção ao meio ambiente, pois o Estado quer na esfera Federal, Estadual ou Municipal passa por dificuldades financeiras graves, o que o impede de tomar para si qualquer pretensão 
de restabelecimento do meio ambiente, cabendo através de conciliação ou outro método consensual de composição de conflito conciliar o interesse estatal e o restabelecimento do meio ambiente a sua anterior situação, a conciliação de prazos, valores e formas técnicas de restabelecimento e ressarcimento dos danos ocorridos é normal e esperada.

Desta forma, verificamos que a aplicação dos métodos consensuais de solução de conflitos, já são acolhidos por grande parte dos doutrinadores e também em vários processos através da conciliação em ações que envolvem o dano ambiental já são realizadas, com os cuidados e proteção ao meio ambiente, com o que o que se espera no futuro é a aplicação dos demais métodos, tais como a arbitragem e a medição em conflitos que envolvam danos ao meio ambiente. Conclui-se pela possibilidade da aplicação dos métodos consensuais de solução de conflito aos processos que tenham por objeto o dano ambiental.

\section{NOTAS FINAIS}

O presente artigo é escrito em momento de grandes alterações na legislação processual civil, com a entrada em vigor do CPC/2015, o qual em consonância para com a Resolução 125 do $\mathrm{CNJ}$, traz os métodos consensuais de solução de conflitos, conciliação, mediação e arbitragem a serem oferecidos pelo Poder Judiciário em um sistema multiportas como opções ao nosso moroso e caro sistema judicial, nem mesmo uma regulamentação à respeito ou a estrutura física dos núcleos e dos centros judiciários de soluções de conflitos ainda não foram definidos. Mas a decisão já foi tomada de ofertar outras opções aos cidadãos que não a sempre judicialização do conflito. Outros países já utilizam os métodos consensuais de solução de conflitos com sucesso, deixando para o Poder Judiciária as demandas de caráter mais complexo e de bens com caráter indisponível.

Verificamos que a hiperjudicialização dos conflitos é um realidade em nosso Poder Judiciário, várias demandas que poderiam ser resolvidas de forma simples são objeto de processos, a paz social, a harmonia e a possibilidade de manutenção do relacionamento entre as partes não são alcançados, havendo sempre um vencedor e um perdedor, a Teoria dos Jogos de John Nash vislumbrou que através 
da cooperação podem as partes obterem uma solução de "soma não zero"da qual mesmo depois do acordo não teriam interesse de alterar a escolha feita, atingindo desta forma ganhos mútuos.

Algumas considerações foram realizadas por sobre a indisponibilidade do meio ambiente, o que impediria a utilização dos métodos consensuais de resolução de conflitos. A importante questão da tributação ambiental foi exposta, como instrumento econômico de proteção ao meio ambiente, não sendo este de cunho punitivo, mas visando sempre a que o empresário faça o planejamento do seu negócio com respeito ao meio ambiente, prevenindo possíveis danos ao meio ambiente, o cunho de incentivo e benefícios fiscais dados pela tributação ambiental é importante instrumento econômico em nossa sociedade de risco global, visando a internalizar os custos ambientais das empresas e repassar aos consumidores para que haja a diminuição dos impactos ou até mesmo a substituição das atividades empresariais poluidoras que degradem o meio ambiente, protegendo está para as futuras gerações. O caráter extrafiscal do tributo ambiental com incentivos e benefícios fiscais vai além de arrecadar valores e passa a produzir efeitos de proteção ambiental efetiva e talvez a única eficaz, pois o que atinge o bolso do cidadão ou empresário é o que resolve.

Foi apresentada proposição singela de implantação de disque-denúncia ambiental e instalação de placas nas empresas com tal indicação, bem como a obrigação das empresas potencialmente geradoras de danos ambientais de fazerem propaganda antes de sua implantação nas comunidades que possam ser afetadas, com a indicação de que denúncias até mesmo anônimas poderiam ser efetivadas, tais sugestões pretendem instigar o debate de propostas simples e de baixo custo, visando a proteção do meio ambiente.

Por fim, analisamos cada um dos métodos consensuais de solução de conflitos, qual sejam, a mediação a conciliação e a arbitragem, as quais no presente cenário de risco ambiental global podem e devem ser utilizadas como uma forma célere e efetiva de proteção ao meio ambiente, verificamos que atualmente grande parte dos doutrinadores entende ser possível e desejável a aplicação dos métodos consensuais de solução de conflito em danos empresariais ambientais, anexamos os números de alguns processos em primeira instância em que ocorreu a conciliação 
em ação civil pública na fase de execução de sentença, demonstrando que a utilização da conciliação em processos que tenham por objeto danos ambientais já é uma realidade, informamos ainda o Decreto 52.201/2007 do Estado de São Paulo que permite a realização de TAC pela administração direta e indireta daquele Estado.

Finalizo com a certeza de que os métodos consensuais de solução de conflito em pouco tempo serão uma realidade, depois de afastado o desconhecimento dos operadores do direito, sendo estes em conjunto com o único meio eficaz na defesa do meio ambiente que é a tributação ambiental, os novos instrumentos a serem trabalhados para que futuras gerações recebam o meio ambiente equilibrado e preservado.

\section{REFERÊNCIAS}

ANTUNES, Paulo de Bessa. Direito ambiental. 11. ed. Rio de Janeiro: LumenJuris, 2008.

BERALDO, Leonardo de Faria.Curso de Arbitragem- nos termos da Lei 9.0307/96, São Paulo: Atlas, 2014.

BUENO, Cássio Scarpinella, Novo Código de Processo Civil- anotado. São Paulo: Saraiva, 2015.

BRASIL. Constituição (1824). Constituição do Império de 1824. Disponível em:<http://www.planalto.gov.br/ccivil_03/Constituicao/Constituicao24.htm>. Acesso em 5 jul. 2018.

BRASIL. Lei $n^{\circ} 6.938$, de 31 de agosto de 1981. Dispõe sobre a Política Nacional do Meio Ambiente, seus fins e mecanismos de formulação e aplicação, e dá outras providências. Disponível em: <http://www.planalto.gov.br/ccivil_03/Leis/L6938.htm>. Acesso em 5 jul. 2018.

SÃO PAULO.Decreto 52.201/2007, de 26 de setembro de 2007. Disponível em: <https://www.al.sp.gov.br/norma/74000>. Acesso em 5 jul. 2018.

GUERRERO, Luis Fernando.Os métodos de solução de conflitos e o processo civil. São Paulo: Atlas, 2015.

LEITE, José Rubens Maroto.Manual de Direito Ambiental, São Paulo,Editora Saraiva, 2015. 
MILARÉ, Édis. Direito do Ambiente, São Paulo, 2015, Ed. Revista dos Tribunais, 2015.

PALMA, Juliana Bonacorsi de.Sanção e acordo na administração pública, São Paulo:Malheiros, 2015.

PANTOJA, Tereza Cristina Gonçalvez. Anotações sobre Arbitragem em Matéria Ambiental.Revista de Arbitragem e Mediação, São Paulo, v. 11, 2007.

TEIXEIRA, Carlos Geraldo, Pagamento por serviços ambientais de proteção às nascentes como forma de sustentabilidade e preservação ambiental. Brasília:

Ed. Centro de Estudos Jurídicos, 2012. 